\title{
Wavelength-Selective Light-Responsive DASA-Functionalized Polymersome Nanoreactors
}

\author{
Omar Rifaie-Graham, ${ }^{\dagger, \ddagger}$, Sebastian Ulrich, ${ }^{\dagger}, \|,+{ }^{\ddagger}$ Nikolas F. B. Galensowske, ${ }^{\ddagger}$ Sandor Balog, ${ }^{\ddagger}$ Mohamed \\ Chami, ${ }^{\S}$ Daniel Rentsch, ${ }^{\#}$ James R. Hemmer, ${ }^{\varnothing}$ Javier Read de Alaniz, ${ }^{\varnothing}$ Luciano F. Boesel, ${ }^{*, \|}$ and Nico \\ Bruns* $* \dot{+}$ \\ $¥$ Adolphe Merkle Institute, University of Fribourg, Chemin des Verdiers 4, 1700 Fribourg, Switzerland \\ " Empa, Swiss Federal Laboratories for Materials Science and Technology, Laboratory for Biomimetic Membranes and \\ Textiles, Lerchenfeldstrasse 5, 9014 St. Gallen, Switzerland \\ ${ }^{\S}$ Department for Biosystems Science and Engineering (D-BSSE), Biozentrum, University of Basel, Mattenstrasse 26, 4056 \\ Basel, Switzerland \\ \# Empa, Swiss Federal Laboratories for Materials Science and Technology, Laboratory for Functional Polymers, \\ Überlandstrasse 129, 8600 Dübendorf, Switzerland \\ ${ }^{\varnothing}$ Department of Chemistry and Biochemistry, University of California, Santa Barbara, California 93106, United States of \\ America
}

KEYWORDS. Bioinspired out-of-equilibrium systems, Donor-Acceptor Stenhouse adducts, photochromic molecules, photoisomerization, block copolymer vesicles, gated nanoreactors

\begin{abstract}
Transient activation of biochemical reactions by visible light and subsequent return to the inactive state in the absence of light is an essential feature of the biochemical processes in photoreceptor cells. To mimic such light-responsiveness with artificial nanosystems, polymersome nanoreactors were developed that can be switched on by visible light, and self-revert fast in the dark at room temperature to their inactive state. Donor-Acceptor Stenhouse Adducts (DASAs), with their ability to isomerize upon irradiation with visible light, were employed to change the permeability of polymersome membranes by switching polarity from a non-polar triene form to a cyclopentenone with increased polarity. To this end, amphiphilic block copolymers containing poly(pentafluorophenyl methacrylate) in their hydrophobic block were synthesized by reversible addition fragmentation chaintransfer (RAFT) radical polymerization and functionalized either with a DASA that is based on Meldrum's acid, or with a novel fast switching pyrazolone-based DASA. These polymers were self-assembled into vesicles. Release of hydrophilic payload could be triggered by light and stopped as soon as the light was turned off. The encapsulation of enzymes yielded photo-responsive nanoreactors that catalyzed reactions only if they were irradiated with light. A mixture of polymersome nanoreactors, one that switches in green light, the other switching in red light, permitted to specifically control the individual reactions of a reaction cascade in one pot by irradiation with varied wavelengths, thus enabling light-controlled wavelength-selective catalysis. The DASA-based nanoreactors demonstrate the potential of DASAs to switch permeability of membranes, and could find application to switch reactions on and off on demand, e.g. in microfluidics or in drug delivery.
\end{abstract}

\section{INTRODUCTION}

Photochemical transformations in which light drives a system to an out-of-equilibrium state are important in nature. ${ }^{1-2}$ When the light stimulus is removed, such systems return to their original state. An example can be found in the mammalian eye which contains a variety of photo-responsive cells that detect different wavelengths and light intensities, ultimately enabling the visual perception of colors and objects. These processes are based on the organic photochrome retinal, and the light-induced photoisomerization from the cis to the trans isomers. ${ }^{4}$ In the dark, the original cis isomer is recovered by enzymatic activity. Without this return to the initial state, the cells would not be able to repeatedly sense light.

Artificial organic photochromes have long fascinated scientists with their ability to switch upon light stimulation between states of different polarity, absorptivity, charge, and molecular shape. ${ }^{5-8}$ This photoswitching ability has been explored for the creation of systems that permit external control with light irradiation. ${ }^{9-18}$ In order to mimic the light-induced transient activation of reaction cascades in photoresponsive cells without having the complex enzymatic systems available, a bio-inspired nanosystem would need to have photochromes that are activated by light, but return to their ground state in the dark at room temperature at a reasonably fast rate. Moreover, these photochromes would have to be implemented into a system that produces a meaningful and detectable signal, e.g. by a catalytic biotransformation. Such a system could be based on nanoreactors that confine enzymatic activity into hollow artificial nanostructures. A further important aspect would be to employ a set of photoswitches, with the individual members reacting to visible light of specific colors, so that different 
wavelengths of light result in the specific activation of different reactions.

Donor-Acceptor Stenhouse adducts (DASAs) represent a fascinating new class of visible light-responsive organic photoswitches that change under visible light irradiation from a colorful and hydrophobic triene-enol, into a colorless and more polar cyclopentenone, but reverse into their initial state when the light stimulus is withdrawn. ${ }^{19-24}$ Interestingly, even in the dark DASAs exist in equilibrium between their two states that, upon light stimulation, is merely shifted completely to one side. Thus, they are prime candidates to realize nanosystems that are shifted out-of-equilibrium as long as the light irradiation continues, and autonomously return to their initial state when the light is absent. As a molecular switch for the visible lightmediated control of materials, a $1^{\text {st }}$ generation of DASAs has already shown potential in a variety of applications ranging from sensors, to drug delivery and photopatterning. ${ }^{25-34}$ Recently, a $2^{\text {nd }}$ generation based on aromatic amine donors greatly expanded both the accessible absorption range (now 450-700 nm) and switchabillity in different environments. ${ }^{35}$ For the incorporation into polymer systems, we presented a modular synthesis of $2^{\text {nd }}$ generation DASAs directly on polymers, allowing to prepare DASA-polymer conjugates. ${ }^{32}$

A promising candidate for nanoreactor systems that mimic the compartmentalization found in cells and organelles are polymer vesicles that self-assemble from amphiphilic block copolymers. $^{36-37}$ They are excellent nanocarrier systems for sensitive cargo, including enzymes for biotransformations, and therapeutics. ${ }^{38-39}$ The membranes of polymersomes usually constitute an impermeable barrier for many compounds, so that they have to be permeabilized if the polymersomes are to be used as nanoreactors or delivery systems. Since polymers can be modified with a variety of functional groups, ${ }^{40}$ polymersomes that self-regulate in the presence of small molecules $^{41}$ or become permeable in response to various stimuli, such as temperature, $\mathrm{pH}$, magnetism, redox potentials, or light have been realized. ${ }^{39,42-43}$ Light is one of the most interesting triggers, as it allows for precise temporal control over the properties of polymersomes. Furthermore, excellent spatial control for the localized activation of a population of polymersomes, for example at a defined point in a microfluidic channel or in a blood vessel near the skin surface, can be achieved. Different types of responses to light have been shown depending on the photosensitive entities; light irradiation might induce degradation of the polymersomes, ${ }^{44-46}$ disassembly, ${ }^{47}$ or rupture of the polymer membrane. ${ }^{48-50}$ All these approaches result in irreversible loss of function and total release of encapsulated cargo. A different approach is rendering the polymer membranes permeable by light. For example, this can be achieved by photoreaction with a hydroxyalkylphenone ${ }^{51}$ or by photo-induced crosslinking. ${ }^{52-54}$ However, these approaches are limited by the inability to switch back to the initial, impermeable state and, therefore, the polymersome membranes remain continuously active. To achieve reversibility, the covalent linking of organic photochromes, such as azobenzene ${ }^{55-57}$ and spiropyran, ${ }^{58}$ into polymersomes has been shown. They change their polarity and molecular shape upon irradiation with UV-light and, thereby, also change the permeability of the polymer membrane while conserving the structural integrity of the vesicles. ${ }^{55-59}$ Even without an additional stimulus, some systems slowly reverse from the metastable permeable to the original impermeable state. However, at room temperature this is usually a slow process in the order of days. ${ }^{60-61}$ In order to quickly switch azobenzeneand spiropyran-based polymersomes to their impermeable state, they were irradiated with light of another wavelength. Thus, two light sources of different wavelengths were needed to achieve sufficiently fast activation and deactivation kinetics. Another serious disadvantage of the established systems is the common need of UV light. It represents a skin hazard and is limited in its penetration depth into tissue, which limit potential biomedical applications. ${ }^{62}$ Furthermore, the harsh UV light may cause adverse effects on many molecular entities. ${ }^{63}$ However, even though intense research activity has been directed in the last years towards the development of visible light-responsive photochromes, ${ }^{64-66}$ to our knowledge, no visible lightresponsive polymersomes or polymersomes with a wavelengthspecific response have been obtained. The transient, lightinduced rearrangement of DASAs as well as their tunable absorption profile makes them prime candidates for the development of polymersomes with temporarily, wavelengthspecific permeabilization of their block copolymer membranes. However, DASAs have so far never been used to switch the permeability of polymersome membranes, nor any other type of polymer membrane.

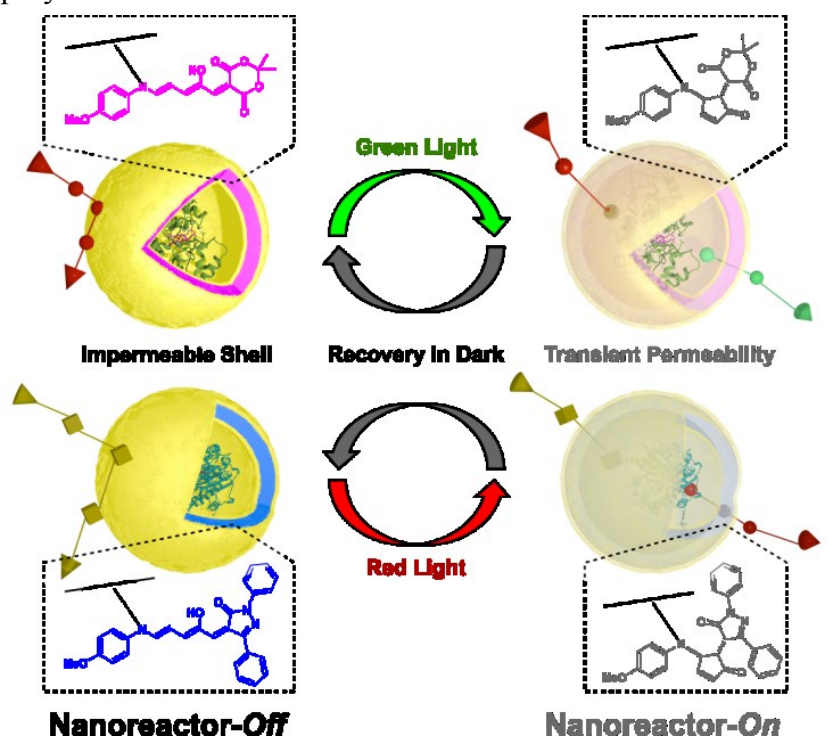

Figure 1. DASA-functionalized visible light responsive nanoreactors. Two sets of enzyme-loaded polymersomes with different DASAs respond to irradiation with lower wavelength (green) or higher wavelength (red) light. The light stimulus switches the DASAs in the hydrophobic leaflet of the polymersome membrane, resulting in an increased permeability of the polymersome membrane and the activation of the enzyme nanoreactor. The polymersomes self-revert to their impermeable state in the dark at room temperature. 


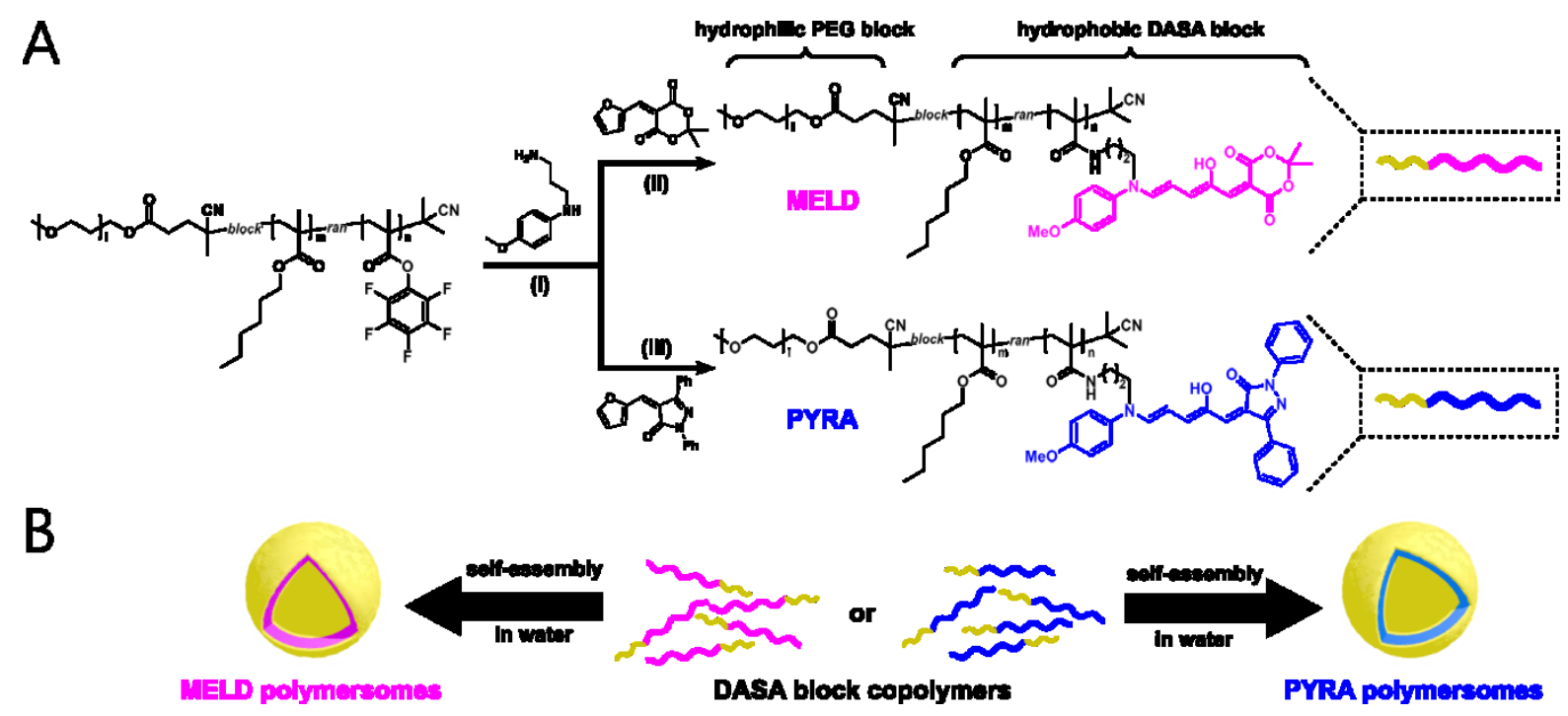

Figure 2. Preparation of DASA-functionalized visible light responsive polymersomes. (a) DASA functionalized block copolymers MELD and PYRA were synthesized in two steps from an active ester block copolymer. Reaction conditions: (i) TEA, THF/DMF 14:3, 45 ${ }^{\circ} \mathrm{C}, 6$ days; (ii) THF, rt, 7 days; (iii) THF, rt, 20 days. (b) Polymersomes were self-assembled by the solvent exchange method.

Herein, we report the development of visible light-responsive polymersomes based on DASA photochromes. To this end we synthesized amphiphilic block copolymers that bear DASAs with tunable absorptivity in their hydrophobic block. To achieve a wider absorption range, we introduce a new DASA that combines absorption at higher wavelengths with excellent switching kinetics. The DASAs were employed as molecular switches to reversely change the permeability of the polymersome membrane with the application of visible light (Figure 1). In addition to the light-responsive release or uptake of cargo into the polymersomes, the polymersomes were loaded with enzymes during self-assembly of the block copolymers to yield visible light-responsive nanoreactors. Their activity could be switched on by light. In the absence of light, the nanoreactors quickly returned to their off state at room temperature. The nanoreactors therefore mimic the working principle of light responsive cells, which are only active as long as they are exposed to light. As light of different wavelengths could be used to selectively switch polymersomes that feature different DASAs, such nanoreactors were used to control the individual reactions of a biochemical reaction cascade, which enabled wavelength specific biocatalysis in one pot.

\section{RESULTS AND DISCUSSION}

Preparation of DASA Polymersomes. To obtain DASAmodified block copolymers, we employed an approach based on the installment of aromatic amine precursors on activated ester polymers, which allow the synthesis of different DASAs directly on the block copolymer backbone. RAFT radical polymerization was employed to obtain amphiphilic block copolymers with tailored molecular weights which could selfassemble into polymersomes. ${ }^{67-68}$ To this end, a poly(ethylene glycol) (PEG) macro-chain transfer agent was synthesized (Scheme S1 and Figure S1) and chain-extended by the random copolymerization of the hydrophobic monomers pentafluorophenyl methacrylate (PFPMA) and hexyl methacrylate (HMA), producing a diblock copolymer with activated ester moieties randomly distributed over the hydrophobic block (Scheme S1). ${ }^{40,}$ 69-70 Gel permeation chromatography showed narrow molecular weight distributions (dispersity $Ð=1.15$ ), a polystyrene-apparent number average molecular weight $\left(M_{n}\right)$ of $13760 \mathrm{~g} \mathrm{~mol}^{-1}$ (Figure S2). The RAFT end-group was substituted with a 2-cyano-isopropyl group by reaction with AIBN to avoid the formation of reactive primary amine end groups in the subsequent amidation (Figure 2a and Scheme S1). ${ }^{71}$

For the modification of the block copolymers with DASAs, the aromatic amine precursor $N$-(4-methoxyphenyl)-1,3diaminepropane (MPDP) was conjugated to the activated ester block copolymer by reaction of its primary amine group with the activated esters of the polymer (Figure 2a), resulting in an aromatic amine-modified block copolymer. The successful conjugation and the completion of the reaction were confirmed by ${ }^{1} \mathrm{H}-\mathrm{NMR}$, diffusion edited ${ }^{1} \mathrm{H}-\mathrm{NMR},{ }^{19} \mathrm{~F}-\mathrm{NMR}$, and infrared (IR) spectroscopy (Figure S3-S5). The degree of functionalization was calculated to be $10.6 \mathrm{~mol} \%$ in the hydrophobic block from the ${ }^{1} \mathrm{H}-\mathrm{NMR}$ data using the characteristic signals of the aromatic amines on the polymer backbone. Subsequent reaction of the aromatic secondary amine with activated furan adducts yielded DASAs on the polymer backbone (Figure 2a).$^{32}$ For this last step, the aromatic amine-bearing block copolymer was divided into two aliquots to enable the synthesis of polymers with equal concentrations of two different DASAs on their hydrophobic blocks. We employed the previously reported Meldrum's acid-based furan adduct, ${ }^{72}$ and a novel five-membered ring pyrazolone-based furan adduct (Figure S6). The respective amphiphilic DASAblock copolymers MELD and PYRA were obtained, as shown by ${ }^{1} \mathrm{H}-\mathrm{NMR}$ and IR spectroscopy (Figure S6 and Figure S7). The DASA-block copoylmers were ready for the subsequent self-assembly into polymersomes (Figure 2b). To obtain nonresponsive control samples of the block copolymers, an aliquot of (PEG- $b$-(PHMA-co-PPFMA)) was modified with hexylamine to yield block copolymer HEX (Scheme S1). 

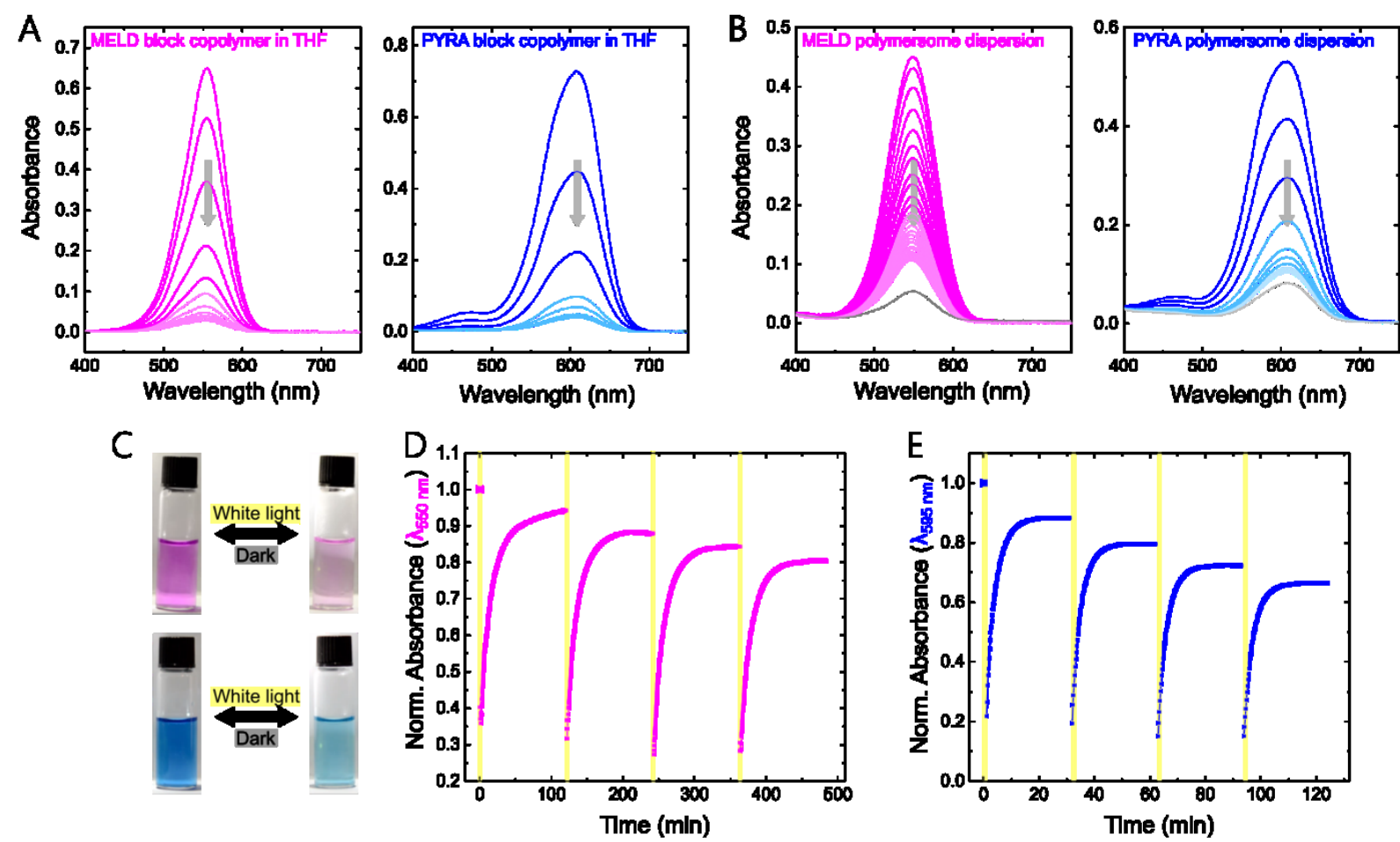

Figure 3. Light switching experiments of DASA block copolymers in solution and of DASA polymersome dispersions. (a) UV-Vis spectra of DASA block copolymer solutions in THF $\left(24 \mu \mathrm{g} \mathrm{mL}^{-1}\right)$ before and during white light irradiation (2 s of light per spectrum). (b) UV-Vis spectra of DASA polymersome dispersions before and during white light irradiation (10 s of light per spectrum). Before recording the last spectra (grey lines), the dispersions were irradiated for additional $3 \mathrm{~min}$. (c) Photographic images of polymersome dispersions before and after white light irradiation. (d/e) Repeated photoswitching of DASA polymersomes by alternating irradiation with white light and recovery of the absorbance in the dark. In each cycle of these experiments the polymersome dispersions were irradiated for 1 min, and the thermal recovery of the absorbance was recorded either at $550 \mathrm{~nm}$ for $120 \mathrm{~min}$ (d, MELD, pink) or at $595 \mathrm{~nm}$ for $30 \mathrm{~min}$ (e, PYRA, blue).

To assess the photochromic properties of the two DASA block copolymers, they were dissolved in THF. The solutions had a deep purple (MELD) or deep blue (PYRA) color (Figure S8). UV-Vis spectra of both solutions are shown in Figure 3a. MELD had a maximum absorbance at $555 \mathrm{~nm}$, and the absorption band of PYRA peaked at $608 \mathrm{~nm}$. The difference between the absorption bands is large enough to provide regions of the spectrum where mostly one DASA absorbs light. When the THF solutions were irradiated with white light, they became colorless within seconds, as the DASAs photoswitched into their colorless closed-ring state (Video S1 and Video S2). Accordingly, white light irradiation resulted in the reduction and, finally, complete disappearance of the absorption peaks, which corresponds to full photoswitching. Notably, PYRA solutions showed a faster decrease of absorbance in comparison to MELD solutions when irradiated under the same conditions, indicating faster photoswitching ability of this compound. MELD and PYRA solutions recovered their full absorbance within 70 and 40 minutes, respectively, when the light was switched off. The thermal recovery of the open state of the DASAs was monitored by UV-Vis spectroscopy until a plateau of the measured absorbance value was reached (Figure S8). For MELD, a recovery halftime of $t_{\mathrm{R} 1 / 2}=10.7$ min was found. PYRA recovered faster with a halftime of $t_{R 1 / 2}=3.8 \mathrm{~min}$. Thus, DASAs are light-triggered molecular switches that relax back to their colorful isomer within minutes in the dark at room temperature. Moreover, these results show that the switching and recovery kinetics are an intrinsic property of each DASA type in accordance with previous reports. ${ }^{19}$ To assess the repeatability of the photoswitching process, both MELD and
PYRA solutions were cycled 10 times between light and dark (Figure S9). The DASA polymers reversibly switched between the colorless and colored state. No reduction in absorption in the colored state could be observed indicating full reversibility. The stability of the DASAs in THF solutions was further tested for two cycles against continuous white light irradiation over periods of $20 \mathrm{~min}$ (Figure S10). No photodegradation of MELD was observed; however, for PYRA the adsorption of the colorful state was reduced by $16 \%$ after the second cycle, indicating that photodegradation occurs with longer continuous irradiation for this DASA type.

Each type of DASA block copolymer was self-assembled in water resulting in hollow polymer vesicles, i.e. polymersomes as observed by cryo-TEM and TEM (Figure 4 and Figure S11). MELD formed smaller unilamellar polymersomes (diameter mostly 30 to $100 \mathrm{~nm}$ ) as well as micelles with a diameter of 30 $\mathrm{nm}$. PYRA formed unilamellar polymersomes with a diameter between 80 and $200 \mathrm{~nm}$. Also, multicompartment polymersomes were observed (Figure S12). The thickness of the polymersome membranes was around $15 \mathrm{~nm}$ in both samples. The samples were further characterized by dynamic light scattering (DLS) and static light scattering (SLS). The determination of $R_{h}$ and $R_{g}$ of MELD assemblies was not possible, as polymersomes and micelles coexisted (Figure 4a). The PYRA assemblies had a radius of gyration $\left(\mathrm{R}_{\mathrm{g}}\right)$ of $60 \mathrm{~nm}$ and hydrodynamic radius $\left(\mathrm{R}_{\mathrm{h}}\right)$ of $61 \mathrm{~nm}$ (Figure $\left.\mathbf{S 1 3}\right)$. The ratio of these values $\left(\rho=\mathrm{R}_{\mathrm{g}} / \mathrm{R}_{\mathrm{h}}=0.96\right)$ was close to 1.0 , accounting for hollow spheres and therefore confirming the formation of vesicles. ${ }^{74}$ Importantly, for both types of DASA polymers the same structures were observed before and after stimulation with 
white light in cryo-TEM (Figure 4) as well as light scattering (Figure S13) experiments. It should be noted that neither micelles nor multicompartment polymersomes interfere with the release and nanoreactor experiments described below since micelles cannot encapsulate hydrophilic dyes or enzymes and are therefore not active in these experiments.
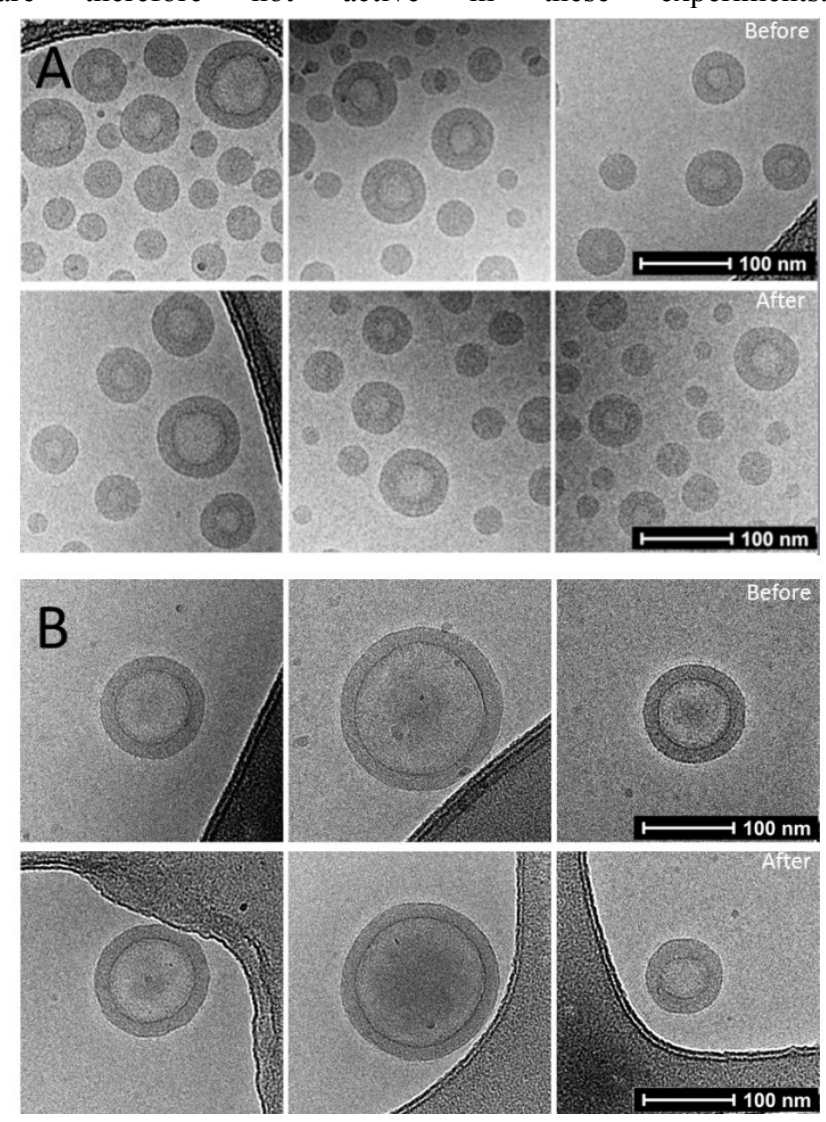

Figure 4. Cryogenic transmission electron microscopy images of DASA-functionalized polymersomes before and after stimulation with visible light for $1 \mathrm{~h}$. (a) MELD polymersomes and micelles. (b) PYRA polymersomes.

The color of aqueous polymersome dispersions closely resembled the one found for the respective THF solutions polymers (Figure 3c). Furthermore, upon white light irradiation, the polymersome dispersions became almost colorless and recovered their color when the light stimulus was withdrawn (Video S3, and Video S4, Figure 3b/c). The corresponding UV-Vis spectra before and after stepwise light irradiation are presented in Figure $\mathbf{3 b}$. The peaks are slightly broader than in the spectra of the THF solutions and the band positions are shifted about $5 \mathrm{~nm}$ to shorter wavelengths. Notably, both dispersions show a reduction in their absorbance when irradiated with white light, but at a much slower rate than the THF solutions and without complete disappearance of the DASA peaks, even after longer additional irradiation for $3 \mathrm{~min}$ (grey curves). Such a difference is not unexpected, since the DASAs in the polymersome membrane are located in a polymer matrix in which the chains are less flexible than in solution. ${ }^{67}$, 75-76 To assess the matrix stiffness, we performed DSC measurements of the DASA block copolymers and found glass transition temperatures $\left(\mathrm{T}_{\mathrm{g}}\right)$ of $30^{\circ} \mathrm{C}$ for MELD and $27^{\circ} \mathrm{C}$ for PYRA (Figure S14). Both values are higher than the $T_{g}$ of a
poly(HMA) homopolymer $\left(-5^{\circ} \mathrm{C}\right)^{76}$, most probably due to the DASA-modified monomer units that raise the $\mathrm{T}_{\mathrm{g}}$ as reported previously. ${ }^{67,72}$

MELD and PYRA display distinctive and different absorption bands in the visible range and therefore react differently to irradiation with light of different wavelengths (Figure S15). MELD polymersomes hardly responded to red light $\left(\lambda_{630} \mathrm{~nm}\right)$, while PYRA polymersomes displayed fast switching kinetics when irradiated with the same wavelength. In turn, MELD polymersomes showed fast switching kinetics when irradiated with green light $\left(\lambda_{525} \mathrm{~nm}\right)$ in comparison to PYRA polymersomes. When MELD and PYRA polymersomes were mixed in one pot and irradiated either with red or green light, shoulders of the absorption band decreased at similar wavelengths to the absorption bands in the experiments with only one DASA polymersome species (Figure S15). To test the repeatability of the photoswitching process of the DASA polymersomes, several cycles of $1 \mathrm{~min}$ white light irradiation and subsequent thermal recovery were monitored (Figure 3d). The recovered absorbance decreased with each cycle. After five cycles, MELD polymersomes returned to $81 \%$ of their initial absorbance, while PYRA polymersomes recovered $66 \%$ of their initial absorbance. The recovery half time was $t_{R 1 / 2}=10.2$ min for MELD polymersomes and $t_{R 1 / 2}=2.1 \mathrm{~min}$ for PYRA polymersomes (Figure S16). Notably, the recovery half times were the same for each irradiation cycle within a SD of 0.63 min (MELD) and $0.05 \mathrm{~min}$ (PYRA). The results indicate that switching of the DASAs in polymersomes was not fully reversible, which is in contrast to the full reversibility of the DASA polymers in solution. Even though some DASAs lost their function, the photoswitching and self-reverting properties of the remaining active DASAs remained the same throughout all the irradiation cycles, indicated by the constant recovery kinetics. A reason for the difference in reversibility between the DASA polymersomes and the dissolved DASA polymers could be that the open, light absorbing state of DASAs is exposed longer to irradiation in the polymersome membrane due to slower switching dynamics within a polymer matrix, resulting in more photodegradation. Irreversibility may also arise from complexation of the DASAs with water molecules since the switching of DASAs is known to be inhibited by polar solvents. ${ }^{72}$ To assess the stability against long-time light irradiation, polymersome dispersions were illuminated twice for $20 \mathrm{~min}$ with white light, allowing the absorbance to return to a constant value in between and after the irradiation (Figure S17). MELD polymersomes recovered $79 \%$ of their initial absorbance whereas the absorbance of PYRA polymersomes returned to $56 \%$ of its initial value. The loss of DASA absorbance is only slightly higher than in the repeated, but short time irradiation cycles. Nevertheless, even after long continuous irradiation, most DASAs in the polymersome membrane retain their photoswitchability and can, therefore, contribute to controlled changes of the properties of the polymersome shell.

Light-induced Release from DASA Polymersomes. One possible application of DASA-functionalized polymersomes is the release of a cargo on demand. To test the light-controlled release of small molecules, the DASA polymers were self- 

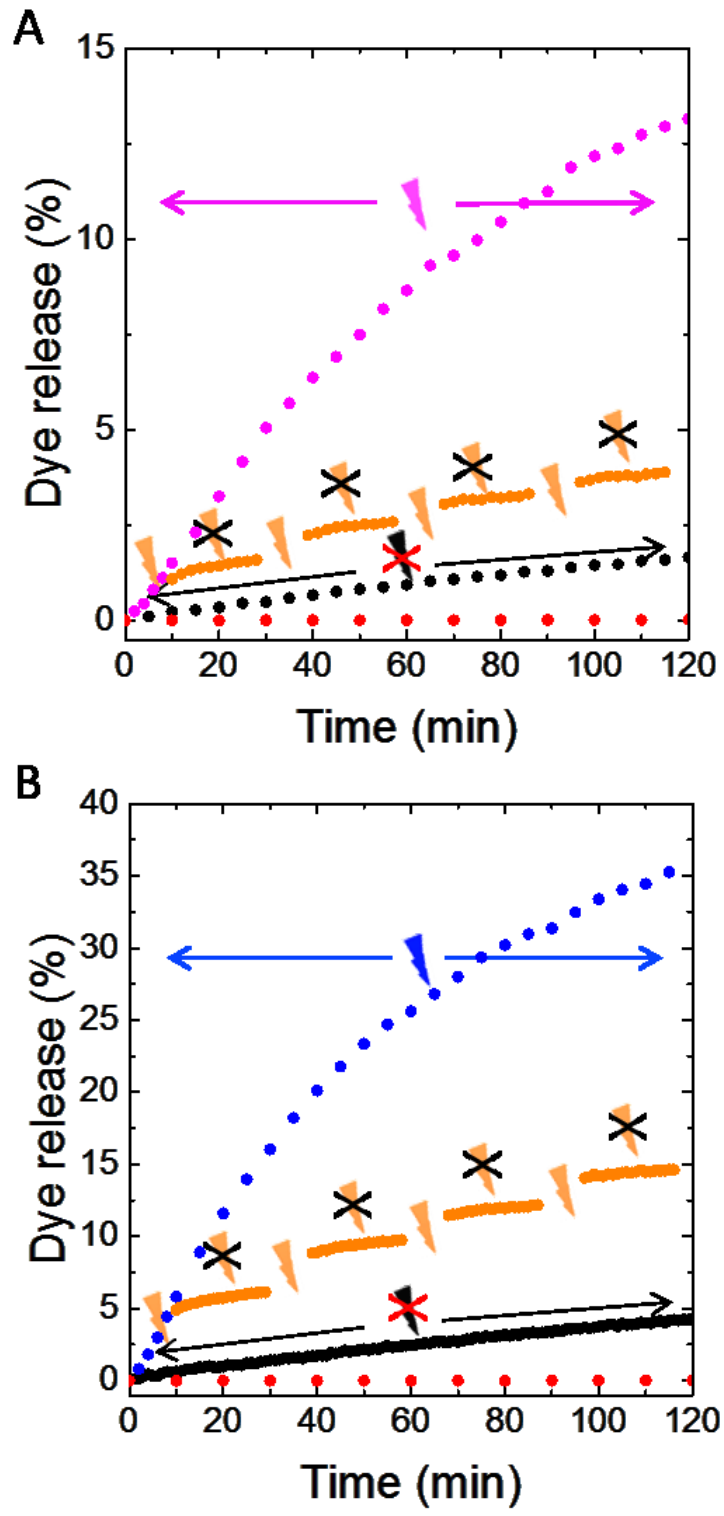

Figure 5. Light-induced release of a model compound from DASA polymersomes. (a) Sodium fluorescein release from MELD polymersomes with continuous white light stimulation $(\bullet)$, alternating light and darkness cycles $(\bullet)$, and in darkness $(\bullet)$. (b) Sodium fluorescein release from PYRA polymersomes with continuous white light stimulation $(\bullet)$, alternating light and darkness cycles $(\bullet)$, and in darkness $(\bullet)$. As a negative control, release of sodium fluorescein during continuous white light irradiation from polymersomes made from the non DASAcontaining HEX is shown in panels A and B $(\bullet)$.

assembled in sodium fluorescein solutions at a self-quenching concentration of the fluorophore, yielding dye loaded polymersomes. The dispersions were dialyzed against water to remove the non-encapsulated sodium fluorescein. When released from the polymersomes, the dye diluted and started to fluoresce, which was monitored by fluorescence spectroscopy (Figure 5). ${ }^{77}$ The DASA polymersomes were only slightly leaky to the fluorescent dye in the dark. In contrast, stimulation of polymersomes with white light resulted in a faster increase of fluorescence, indicating that the vesicle membrane became more permeable for fluorescein. MELD polymersomes released
$13 \%$ (Figure 5a) of their cargo within two hours. PYRA polymersomes released $35 \%$ (Figure 5b) of the dye in the same period. The increase in membrane permeability is most likely caused by the increase in dipole moment and a change into a bulkier molecular shape of the DASAs when they switch from their triene form into the cyclopentenone isomer. This process makes the hydrophobic leaflet of the membrane slightly more hydrophilic, and as a result more permeable for water soluble molecules. The difference in dye release between the two kinds of polymersomes could be caused by the different switching speed of the MELD and PYRA polymersomes and by the different bulkiness of the two DASA types, as the pyrazolonebased DASA presents two phenyl substituents. As a control, polymer vesicles made from HEX were also loaded with fluorescein. Fluorescence emission did not increase when applying white light for a period of $2 \mathrm{~h}$. Thus, polymersomes that lacked DASAs in their membrane were not photoresponsive. Fluorescein-loaded DASA polymersomes were also subjected to alternating cycles of white light and darkness. Fluorescence increased fast with the application of light, but became substantially slower in the absence of light. Thus, the polymersome membranes could be reversibly switched between a high and a low permeability state for fluorescein. However, within four light-dark cycles, the efficiency of permeabilization decreased, indicating that the systems are only intermittently permeable for sodium fluorescein for a limited number of photoswitching cycles. We hypothesize that this phenomenon is due to the loss of switching ability of DASA polymersomes upon repeated light exposure, as discussed above.

A series of experiments was performed to prove that the release of cargo from DASA polymersomes was due to a change in permeability of the polymersome membrane or simply due to the disassembly of the vesicles with the application of light. First, it was shown that the polymersomes could also take up dye when irradiated with white light. To this end, empty DASA polymersomes were introduced into a concentrated solution of sodium fluorescein (i.e. above selfquenching concentration). Then, the dispersion of polymersomes was irradiated with white light for a period of 2 $\mathrm{h}$. The dispersions were dialyzed against water until no fluorescence was observed outside of the dialysis membrane. The dispersion of the DASA-functionalized polymer vesicles fluoresced (Figure S18), which confirms that the vesicles were able to take up the fluorescent dye when irradiated with light, and excludes that the polymersomes disassembled. Subsequently, these dye-loaded polymersomes were irradiated with light for a period of one hour. The fluorescence of the sample increased over time, indicating that the polymersomes could release their cargo again with the application of light. Finally, TEM micrographs taken after release of the dye showed polymersomes, indicating that, in agreement with the cryoTEM and light scattering data discussed above, the polymersomes remained intact during the release experiments.

DASA-based

Light-responsive

Biocatalytic Nanoreactors. To show that the DASA polymersomes can be used as light-responsive nanoreactors whose biocatalytic activity can be switched on by light and which autonomously switched off in the dark, we encapsulated horseradish peroxidase (HRP) into MELD polymersomes during the selfassembly of the block copolymers. HRP catalyzes oxidation reactions with hydrogen peroxide. A variety of chromogenic and fluorogenic substrates are available to assess the activity of 
HRP. ${ }^{78}$ For example, pyrogallol reacts with hydrogen peroxide at a constant rate to produce the yellow-to-brown purpurogallin (Figure S19). The rate of this reaction drastically increases in the presence of HRP. Therefore, the HRP-loaded nanoreactors were introduced into solutions of hydrogen peroxide and pyrogallol, and were irradiated

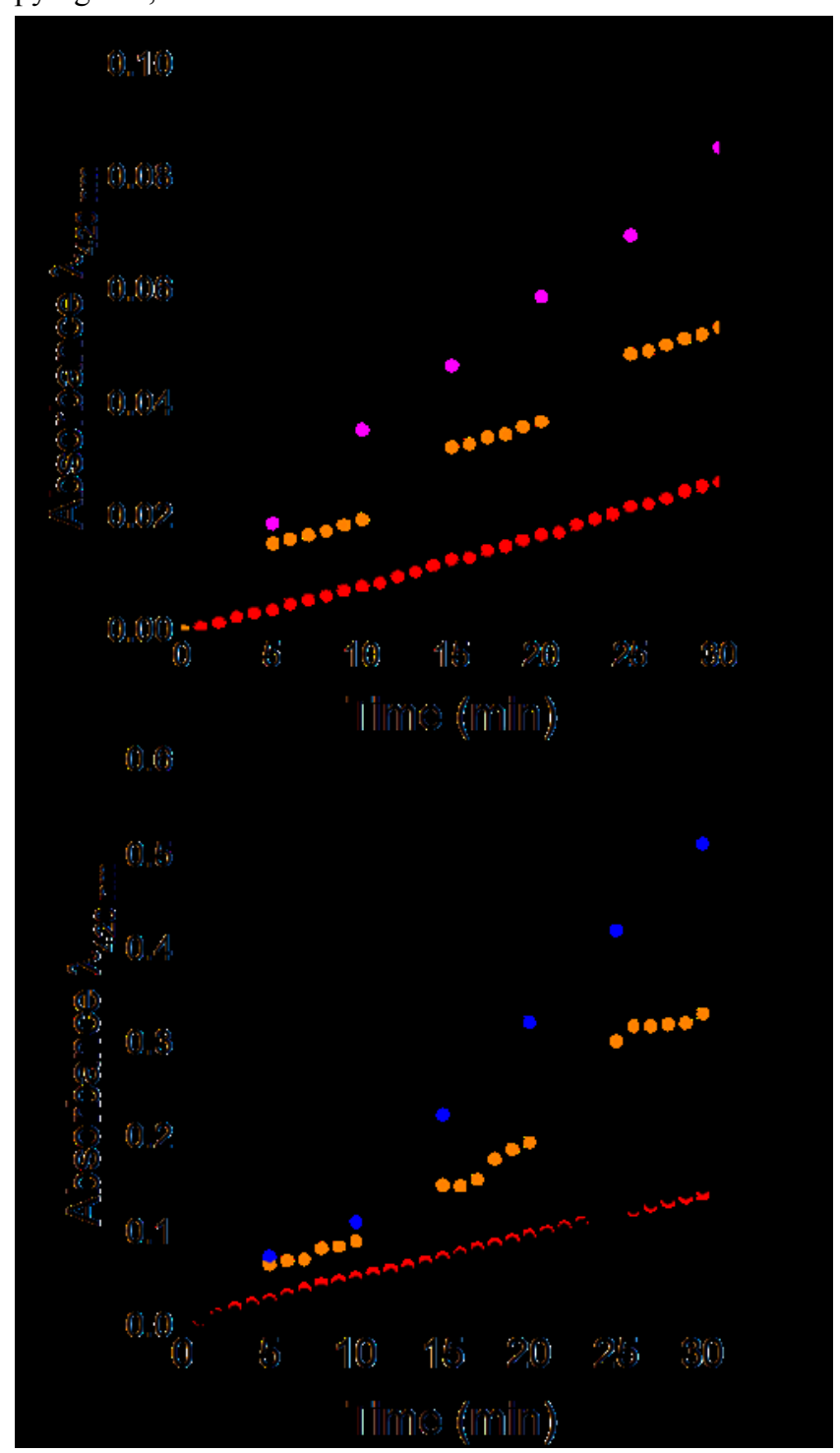

Figure 6. Light-switchable DASA-based biocatalytic nanoreactors. (a) Catalysis of the reaction of pyrogallol with hydrogen peroxide by HRP in MELD-polymersomes: continuous irradiation with white light $(\bullet)$, alternating light and darkness cycles $(\bullet)$, and in darkness $(\bullet)$. For comparison, the non-catalyzed blank reaction is also presented (•). (b) Catalysis of the oxidation of glucose by GOx in PYRA polymersomes as determined by the pyrogallol assay, using free HRP as a developer: continuous irradiation with white light $(\bullet)$, alternating light and darkness cycles $(\bullet)$, and in darkness $(\bullet)$. For comparison, the non-catalyzed blank reaction is also presented $(\bullet)$.

continuously with white light. The formation of purpurogallin was followed by UV-Vis measurements at $420 \mathrm{~nm}$. The absorbance increased continuously for at least $30 \mathrm{~min}$ (Figure 6a) at a higher rate than the blank reaction that lacked nanoreactors. The catalytic activity was quantified to be 0.013
$\%$ that of the free enzyme, indicating a limited diffusion of the reactants through the polymersome membrane. The reaction could also be interrupted by storing the sample in darkness and, subsequently, reinitiated by irradiation with white light. Even though the DASAs in the polymersomes need more than $t_{\mathrm{R} 1 / 2}=$ $10.2 \mathrm{~min}$ for MELD and $t_{\mathrm{R} 1 / 2}=2.1 \mathrm{~min}$ for PYRA to return to their original state in the dark (vide supra), the switch off of activity happens within the time needed to transfer the cuvettes from the light source to the dark compartment of the spectrometer, i.e. within less than a minute. Most likely, the polymersome membrane already becomes impermeable when a small portion of the DASAs has thermally reverted to the open form. When the reactions were performed in darkness, the reaction rate did not differ from the blank reactions, suggesting that the nanoreactors were impermeable to the assay compounds in the dark.

Glucose oxidase (GOx) catalyzes the reaction of $\beta$-D-glucose with oxygen to form D-glucono-1,5-lactone and hydrogen peroxide. This reaction is therefore often employed in cascade biochemical transformations followed by an HRP-catalyzed oxidation (Figure S19). ${ }^{79}$ We encapsulated GOx into PYRA polymersomes to yield a photoresponsive nanoreactor which could produce hydrogen peroxide in the presence of glucose. To follow the reaction spectrophotometrically, we added pyrogallol and HRP into the nanoreactor dispersion, i.e. into the media that surrounds the nanoreactors. A blank reaction at a constant rate could be observed in the absence of the nanoreactors. When white light was applied, purpurogallin formed at an increased rate over the blank reaction, meaning that the GOx-loaded PYRA nanoreactor produced hydrogen peroxide (Figure 6b). The catalytic activity was quantified to be $1.1 \%$ that of the free enzyme. As in MELD nanoreactors, the reduced enzymatic activity is an indication of a reduced permeation of the reactants across the polymersome membrane. Catalytic purpurogallin formation was not observed when the sample was kept in the dark, i.e. the nanoreactors only generated hydrogen peroxide when irradiated with light. The reaction could also be repeatedly stopped by switching the light off and restarted by switching it on. Again, the interruption of enzymatic activity in the dark happened within the time needed to record the first data points, even though the full thermal recovery of PYRA polymersomes is much slower.

Light makes the membrane of DASA polymersomes permeable for enzyme substrates, and the membranes selfrevert fast to their non-permeable state at room temperature as soon as light is removed. Therefore, enzyme-loaded DASA polymersomes are ideally suited to catalyze reactions on demand. Moreover, the reinitiation experiments confirm the integrity of the polymersome membranes upon irradiation with light. If the polymers would disassemble, the enzymes would be liberated and the reactions would continue in the dark.

To show that also other combinations of the two types of DASA polymersomes and the two enzymes result in light responsive nanoreactors with similar properties, HRP was encapsulated into PYRA polymersomes and GOx into MELD polymersomes. Also these nanoreactors could be continuously activated by the irradiation with white light, the catalysis could be initiated and stopped multiple times, and catalytic formation of purpurogallin was not observed when the samples were kept in darkness (Figure S20). Thus, the type of enzyme does not affect the functionality of the DASA polymersomes. This 
strongly suggests that the polymersomes can be employed as light-gated nanoreactors for a large variety of other enzymes.

Wavelength-selective Biocatalysis. As the two types of DASAs absorb light and switch at different wavelengths it

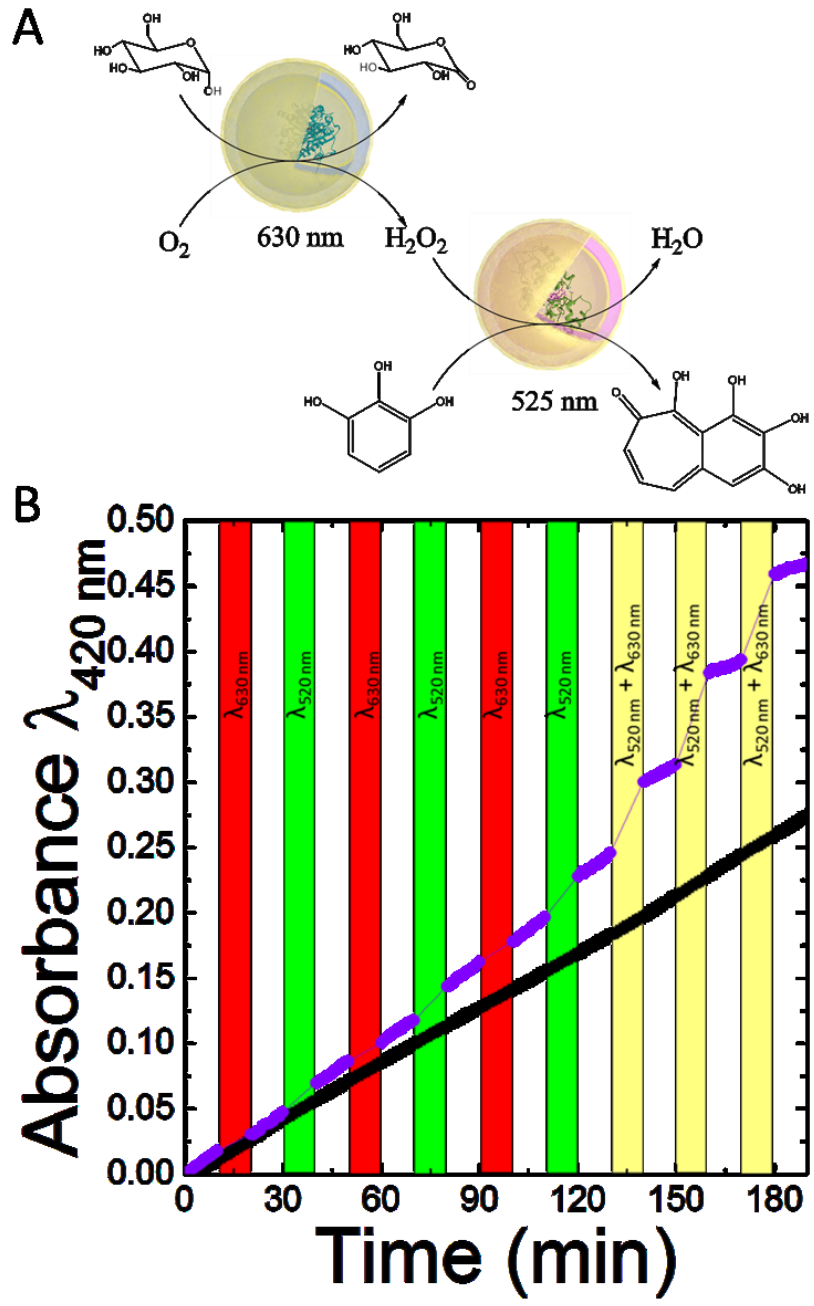

Figure 7. Wavelength-specific DASA-based biocatalytic nanoreactors. GOx-HRP cascade reaction catalyzed by a mixed dispersion of MELD-HRP and PYRA-GOx nanoreactors, and pyrogallol assay to probe the light-response of this cascade reaction (purple). The dispersion was exposed to three cycles of darkness/red light/darkness/green light, followed by three cycles of darkness and joint green and red light irradiation. As a comparison, the blank reaction without nanoreactors is presented (black).

should be possible to control the two reactions of the GOx-HRP cascade separately by light of different colors. The cascade reaction was carried out with each biocatalyst being encapsulated in one type of the DASA polymersomes. A mixture of PYRA-GOx and MELD-HRP nanoreactors (enzyme molar ratio 1:10) was introduced into solutions of pyrogallol and glucose. When the reaction mixtures were kept in the dark, the formation of purpurogallin was similar to the blank reaction (Figure S21), indicating that the polymersomes were impermeable for the substrates and intermediate products. Irradiation with red light $(\lambda=630 \mathrm{~nm})$ did not increase the reaction rate of the cascade reaction as red light only activates the PYRA-GOx polymersomes, while the MELD-HRP nanoreactors remain inactive. In contrast, the reaction rate increased when the system was irradiated with green light $(\lambda=$ $525 \mathrm{~nm}$ ), as both nanoreactors systems absorb light at $525 \mathrm{~nm}$. Though MELD polymersomes photoswitched faster than PYRA polymersomes when irradiated at $525 \mathrm{~nm}$ (Figure S15), the photoswitching of PYRA was sufficient to enable the permeation of substrates in and out and their catalytic reaction inside of the PYRA-GOx nanoreactors.

In a further experiment, a reaction mixture was repeatedly irradiated with alternating cycles of red and green light (Figure 7). When red light was applied, purpurogallin formation did not increase. Each cycle of green light irradiation triggered the formation of purpurogallin; in addition to the slight activation of PYRA-GOx, the hydrogen peroxide that was produced but not consumed during the red light irradiation triggered the oxidation of pyrogallol during the green light irradiation. After three cycles of red and green light irradiation, light of the two wavelengths was applied at the same time. A drastic increase in absorbance over time was observed, indicating that the diffusion limitations of the substrates decreased by a higher photoswitching of the systems, leading to higher nanoreactor reactivity. The increase of reactivity of the system could be due to higher photoswitching efficiency, as irradiation was produced with a broader range of the visible spectrum. These experiments indicate that wavelength specific biocatalysis can be achieved in a predictable manner by employing different DASA polymersomes with distinct absorption profiles that permit their selective activation.

\section{CONCLUSIONS}

Functionalization of block copolymers with DASAs resulted in polymersome membranes that become permeable in the presence of visible light and almost instantaneously return to their impermeable state when the stimulus is withdrawn. As different DASAs possess different colors, the wavelength at which the polymersomes become permeable can be tuned by the synthesis of the DASAs on the block copolymers. The DASA polymersomes were shown to repeatedly start and stop the release of a model compound and, by encapsulating enzymes into them, were turned into nanoreactors whose activity was switched on during visible light irradiation. The transient, wavelength-selective activation of the DASA polymersomes mimics the properties of photoreceptors in cells, which would not allow for vision if they would remain in their activated state for longer periods after a light stimulation. The DASA polymersomes could find applications in microfluidics to trigger reactions at defined sites within the microchannels by light, allowing both temporal and spatial control over a reaction without the need for additional channels or heterocatalysts. Moreover, these systems could be interesting candidates for pharmacological applications. For instance, a drug delivery system that becomes activated in the presence of light would release at the irradiation site, but stop release as soon as it would move with the blood flow away from the site of irradiation. The presented work introduces a strategy towards DASA polymersomes that can be readily expanded with new furan adduct precursors that will allow the synthesis of new DASAs on the same block copolymer. We hypothesize that systems containing DASAs with absorbance bands even further apart in the visible spectrum would allow an even finer control of wavelength selective reactions and cascades. Furthermore, it 
can be easily envisioned that the presence of a larger number of different DASA-functionalized nanoreactors could generate much more complex reaction systems in which each individual reaction step could be controlled by light of a specific color, or in reaction logics in which a reaction only proceeds if two stimuli are present at the same time.

\section{ASSOCIATED CONTENT}

Supporting Information. Experimental details and addition results (PDF). Videos of DASA polymersome dispersion switching with white light irradiation (video files). The Supporting Information is available free of charge on the ACS Publications website.

\section{AUTHOR INFORMATION}

\section{Corresponding Authors}

*E-Mail: luciano.boesel@empa.ch

* E-Mail: nico.bruns@unifr.ch

\section{Author Contributions}

$\dagger$ O.R.-G. and S.U. contributed equally.

\section{ACKNOWLEDGMENT}

This work was supported by the Swiss National Science Foundation through the National Center of Competence in Research (NCCR) Bio-Inspired Materials and the projects PP00P2 144697, PP00P2 172927, 206021 150638/1 and 200021 172609 ("Teleflow"). We thank the California NanoSystem Institute (CNSI) Challenge Grant Program for support. We thank Samuel Raccio (Adolphe Merkle Institute, University of Fribourg) for experimental help with gel permeation chromatography.

\section{REFERENCES}

1. Merindol, R.; Walther, A., Materials learning from life: concepts for active, adaptive and autonomous molecular systems. Chem. Soc. Rev. 2017, 46 (18), 5588-5619.

2. Kathan, M.; Hecht, S., Photoswitchable molecules as key ingredients to drive systems away from the global thermodynamic minimum. Chem. Soc. Rev. 2017, 46 (18), 5536-5550.

3. Cao, D.; Pokorny, J.; Smith, V. C.; Zele, A. J., Rod contributions to color perception: linear with rod contrast. Vision Res. 2008, 48 (26), 2586-2592.

4. $\quad$ Kiser, P. D.; Golczak, M.; Palczewski, K., Chemistry of the retinoid (visual) cycle. Chem. Rev. 2013, 114 (1), 194-232.

5. Russew, M. M.; Hecht, S., Photoswitches: From Molecules to Materials. Adv. Mater. 2010, 22 (31), 3348-3360.

6. Zhang, J. J.; Zou, Q.; Tian, H., Photochromic Materials: More Than Meets The Eye. Adv. Mater. 2013, 25 (3), 378-399.

7. Irie, M., Photochromism: Memories and SwitchesIntroduction. Chem. Rev. 2000, 100 (5), 1683-1684.

8. Wang, L.; Li, Q., Photochromism into nanosystems: towards lighting up the future nanoworld. Chem. Soc. Rev. 2018, (47), 10441097.

9. Lerch, M. M.; Hansen, M. J.; Velema, W. A.; Szymanski, W.; Feringa, B. L., Orthogonal photoswitching in a multifunctional molecular system. Nat. Commun. 2016, 7, 12054.

10. Jochum, F. D.; Théato, P., Temperature- and lightresponsive smart polymer materials. Chem. Soc. Rev. 2013, 42 (17), $7468-7483$

11. Willner, I.; Rubin, S., Control of the structure and functions of biomaterials by light. Angew. Chem. Int. Ed. 1996, 35 (4), 367-385.
12. Hecht, S., Optical Switching of Hierarchical Self-Assembly: Towards "Enlightened" Materials. Small 2005, $l$ (1), 26-29.

13. Li, A. D. Q.; Zhan, C.; Hu, D.; Wan, W.; Yao, J., Photoswitchable Nanoprobes Offer Unlimited Brightness in Frequency-Domain Imaging. J. Am. Chem. Soc. 2011, 133 (20), 76287631.

14. Osborne, E. A.; Jarrett, B. R.; Tu, C.; Louie, A. Y., Modulation of T2 Relaxation Time by Light-Induced, Reversible Aggregation of Magnetic Nanoparticles. J. Am. Chem. Soc. 2010, 132 (17), 5934-5935.

15. Achilleos, D. S.; Hatton, T. A.; Vamvakaki, M., LightRegulated Supramolecular Engineering of Polymeric Nanocapsules. $J$. Am. Chem. Soc. 2012, 134 (13), 5726-5729.

16. Willner, I.; Rubin, S.; Shatzmiller, R.; Zor, T., Reversible light-stimulated activation and deactivation of .alpha.-chymotrypsin by its immobilization in photoisomerizable copolymers. J. Am. Chem. Soc. 1993, 115 (19), 8690-8694.

17. Vlassiouk, I.; Park, C.-D.; Vail, S. A.; Gust, D.; Smirnov, S., Control of Nanopore Wetting by a Photochromic Spiropyran: A LightControlled Valve and Electrical Switch. Nano Lett. 2006, 6 (5), 10131017 .

18. Jia, S.; Fong, W.-K.; Graham, B.; Boyd, B. J., Photoswitchable molecules in long-wavelength light-responsive drug delivery: from molecular design to applications. Chem. Mater. 2018, 30 (9), 2873-2887

19. Helmy, S.; Oh, S.; Leibfarth, F. A.; Hawker, C. J.; Read de Alaniz, J., Design and Synthesis of Donor-Acceptor Stenhouse Adducts: A Visible Light Photoswitch Derived from Furfural. J. Org. Chem 2014, 79 (23), 11316-11329.

20. Ahrens, J.; Bian, T.; Vexler, T.; Klajn, R., Irreversible Bleaching of Donor-Acceptor Stenhouse Adducts on the Surfaces of Magnetite Nanoparticles. ChemPhotoChem 2017, 1 (5), 230-236.

21. Laurent, A. D.; Medved', M.; Jacquemin, D., Using TimeDependent Density Functional Theory to Probe the Nature of DonorAcceptor Stenhouse Adduct Photochromes. ChemPhysChem 2016, 17 (12), 1846-1851.

22. Lerch, M. M.; Wezenberg, S. J.; Szymanski, W.; Feringa, B. L., Unraveling the Photoswitching Mechanism in Donor-Acceptor Stenhouse Adducts. J. Am. Chem. Soc. 2016, 138 (20), 6344-6347.

23. Mallo, N.; Brown, P. T.; Iranmanesh, H.; MacDonald, T. S.; Teusner, M. J.; Harper, J. B.; Ball, G. E.; Beves, J. E., Photochromic switching behaviour of donor-acceptor Stenhouse adducts in organic solvents. Chem. Commun. 2016, 52 (93), 13576-13579.

24. Lerch, M. M.; Szymański, W.; Feringa, B. L., The (photo) chemistry of Stenhouse photoswitches: guiding principles and system design. Chem. Soc. Rev. 2018, 47 (6), 1910-1937.

25. Balamurugan, A.; Lee, H.-i., A Visible Light Responsive On-Off Polymeric Photoswitch for the Colorimetric Detection of Nerve Agent Mimics in Solution and in the Vapor Phase. Macromolecules 2016, 49 (7), 2568-2574.

26. Diaz, Y. J.; Page, Z. A.; Knight, A. S.; Treat, N. J.; Hemmer, J. R.; Hawker, C. J.; Read de Alaniz, J., A Versatile and Highly Selective Colorimetric Sensor for the Detection of Amines. Chem. Eur J. 2017, 23 (15), 3562-3566.

27. Dolinski, N. D.; Page, Z. A.; Eisenreich, F.; Niu, J.; Hecht, S.; Read de Alaniz, J.; Hawker, C. J., A Versatile Approach for In Situ Monitoring of Photoswitches and Photopolymerizations. ChemPhotoChem 2017, 1 (4), 125-131.

28. Zhong, D.; Cao, Z.; Wu, B.; Zhang, Q.; Wang, G., Polymer dots of DASA-functionalized polyethyleneimine: Synthesis, visible light/pH responsiveness, and their applications as chemosensors. Sens. Actuators, B 2018, 254, 385-392.

29. Poelma, S. O.; Oh, S. S.; Helmy, S.; Knight, A. S.; Burnett G. L.; Soh, H. T.; Hawker, C. J.; de Alaniz, J. R., Controlled drug release to cancer cells from modular one-photon visible lightresponsive micellar system. Chem. Commun. 2016, 52 (69), 1052510528.

30. Jia, S.; Du, J. D.; Hawley, A.; Fong, W.-K.; Graham, B.; Boyd, B. J., Investigation of Donor-Acceptor Stenhouse Adducts as New Visible Wavelength-Responsive Switching Elements for LipidBased Liquid Crystalline Systems. Langmuir 2017, 33 (9), 2215-2221. 
31. Mason, B.; Whittaker, M.; Hemmer, J.; Arora, S.; Harper, A.; Alnemrat, S.; McEachen, A.; Helmy, S.; Read de Alaniz, J.; Hooper, J., A temperature-mapping molecular sensor for polyurethanebased elastomers. Appl. Phys. Lett. 2016, 108 (4), 041906.

32. Ulrich, S.; Hemmer, J. R.; Page, Z. A.; Dolinski, N. D.; Rifaie-Graham, O.; Bruns, N.; Hawker, C. J.; Boesel, L. F.; Read de Alaniz, J., Visible light-responsive DASA-polymer conjugates. ACS Macro Lett. 2017, 6 (7), 738-742.

33. Sinawang, G.; Wu, B.; Wang, J.; Li, S.; He, Y., Polystyrene Based Visible Light Responsive Polymer with Donor-Acceptor Stenhouse Adduct Pendants. Macromol. Chem. Phys. 2016, 217 (21), 2409-2414.

34. Singh, S.; Friedel, K.; Himmerlich, M.; Lei, Y.; Schlingloff, G.; Schober, A., Spatiotemporal photopatterning on polycarbonate surface through visible light responsive polymer bound DASA compounds. ACS Macro Lett. 2015, 4 (11), 1273-1277.

35. Hemmer, J. R.; Poelma, S. O.; Treat, N.; Page, Z. A.; Dolinski, N. D.; Diaz, Y. J.; Tomlinson, W.; Clark, K. D.; Hooper, J. P.; Hawker, C., Tunable visible and near infrared photoswitches. J. Am. Chem. Soc. 2016, 138 (42), 13960-13966.

36. Marguet, M.; Bonduelle, C.; Lecommandoux, S., Multicompartmentalized polymeric systems: towards biomimetic cellular structure and function. Chem. Soc. Rev. 2013, 42 (2), 512-529.

37. Küchler, A.; Yoshimoto, M.; Luginbühl, S.; Mavelli, F.; Walde, P., Enzymatic reactions in confined environments. Nature Nanotecnol. 2016, 11 (5), 409.

38. Peters, R. J.; Louzao, I.; van Hest, J. C., From polymeric nanoreactors to artificial organelles. Chem. Sci. 2012, 3 (2), 335-342.

39. Palivan, C. G.; Goers, R.; Najer, A.; Zhang, X.; Car, A.; Meier, W., Bioinspired polymer vesicles and membranes for biological and medical applications. Chem. Soc. Rev. 2016, 45 (2), 377-411.

40. Das, A.; Théato, P., Activated Ester Containing Polymers: Opportunities and Challenges for the Design of Functional Macromolecules. Chem. Rev. 2015, 116 (3), 1434-1495.

41. Che, H.; Cao, S.; van Hest, J. C., Feedback-induced temporal control of "breathing" polymersomes to create self-adaptive nanoreactors. J. Amer. Chem. Soc. 2018, 140 (16), 5356-5359.

42. Renggli, K.; Baumann, P.; Langowska, K.; Onaca, O.; Bruns, N.; Meier, W., Selective and Responsive Nanoreactors. $A d v$ Funct. Mater. 2011, 21 (7), 1241-1259.

43. Gaitzsch, J.; Huang, X.; Voit, B., Engineering Functional Polymer Capsules toward Smart Nanoreactors. Chem. Rev. (Washington, DC, U. S.) 2016, 116 (3), 1053-1093.

44. Cabane, E.; Malinova, V.; Menon, S.; Palivan, C. G.; Meier, $\mathrm{W}$., Photoresponsive polymersomes as smart, triggerable nanocarriers. Soft Matter 2011, 7 (19), 9167-9176.

45. Nazemi, A.; Gillies, E. R., Dendrimersomes with photodegradable membranes for triggered release of hydrophilic and hydrophobic cargo. Chem. Commun. 2014, 50 (76), 11122-11125.

46. Liu, G.; Wang, X.; Hu, J.; Zhang, G.; Liu, S., Selfimmolative polymersomes for high-efficiency triggered release and programmed enzymatic reactions. J. Am. Chem. Soc. 2014, 136 (20), $7492-7497$.

47. Wang, Y.; Han, P.; Xu, H.; Wang, Z.; Zhang, X.; Kabanov, A. V., Photocontrolled self-assembly and disassembly of block ionomer complex vesicles: A facile approach toward supramolecular polymer nanocontainers. Langmuir 2009, 26 (2), 709-715.

48. Amstad, E.; Kim, S. H.; Weitz, D. A., Photo-and thermoresponsive polymersomes for triggered release. Angew. Chem. 2012, 124 (50), 12667-12671.

49. Griepenburg, J. C.; Sood, N.; Vargo, K. B.; Williams, D.; Rawson, J.; Therien, M. J.; Hammer, D. A.; Dmochowski, I. J., Caging metal ions with visible light-responsive nanopolymersomes. Langmuir 2015, 31 (2), 799-807.

50. Peyret, A.; Ibarboure, E.; Tron, A.; Beauté, L.; Rust, R.; Sandre, O.; McClenaghan, N. D.; Lecommandoux, S., Polymersome Popping by Light-Induced Osmotic Shock under Temporal, Spatial, and Spectral Control. Angew Chem Int Ed Engl 2017, 56 (6), 15661570 .

51. Spulber, M.; Najer, A.; Winkelbach, K.; Glaied, O.; Waser, M.; Pieles, U.; Meier, W.; Bruns, N., Photoreaction of a hydroxyalkyphenone with the membrane of polymersomes: a versatile method to generate semipermeable nanoreactors. J. Am. Chem. Soc. 2013, 135 (24), 9204-9212.

52. Gaitzsch, J.; Appelhans, D.; Gräfe, D.; Schwille, P.; Voit, B., Photo-crosslinked and $\mathrm{pH}$ sensitive polymersomes for triggering the loading and release of cargo. Chem. Commun. 2011, 47 (12), 34663468 .

53. Gaitzsch, J.; Appelhans, D.; Wang, L.; Battaglia, G.; Voit, B., Synthetic Bio-Nanoreactor: Mechanical and Chemical Control of Polymersome Membrane Permeability. Angew. Chem. Int. Ed. 2012, 51 (18), 4448-4451.

54. Wang, X.; Liu, G.; Hu, J.; Zhang, G.; Liu, S., Concurrent Block Copolymer Polymersome Stabilization and Bilayer Permeabilization by Stimuli-Regulated "Traceless" Crosslinking. Angewandte Chemie International Edition 2014, 53 (12), 3138-3142.

55. Yan, B.; Tong, X.; Ayotte, P.; Zhao, Y., Light-responsive block copolymer vesicles based on a photo-softening effect. Soft Matter 2011, 7 (21), 10001-10009.

56. Blasco, E.; Serrano, J. L.; Piñol, M.; Oriol, L., Light responsive vesicles based on linear-dendritic block copolymers using azobenzene-aliphatic codendrons. Macromolecules 2013, 46 (15), $5951-5960$

57. Yan, B.; He, J.; Ayotte, P.; Zhao, Y., Optically triggered dissociation of kinetically stabilized block copolymer vesicles in aqueous solution. Macromol. Rapid Commun. 2011, 32 (13), 972-976.

58. Wang, X.; Hu, J.; Liu, G.; Tian, J.; Wang, H.; Gong, M.; Liu, S., Reversibly Switching Bilayer Permeability and Release Modules of Photochromic Polymersomes Stabilized by Cooperative Noncovalent Interactions. J. Am. Chem. Soc. 2015, 137 (48), 15262-15275.

59. Huang, C. Q.; Wang, Y.; Hong, C. Y.; Pan, C. Y., Spiropyran-Based Polymeric Vesicles: Preparation and Photochromic Properties. Macromol. Rapid Commun. 2011, 32 (15), 1174-1179.

60. Jochum, F. D.; Theato, P., Temperature and light sensitive copolymers containing azobenzene moieties prepared via a polymer analogous reaction. Polymer 2009, 50 (14), 3079-3085.

61. Flannery Jr, J. B., Photo-and thermochromic transients from substituted 1', 3', 3'-trimethylindolinobenzospiropyrans. J. Am. Chem. Soc. 1968, 90 (21), 5660-5671.

62. Amjadi, M.; Sheykhansari, S.; Nelson, B. J.; Sitti, M., Recent Advances in Wearable Transdermal Delivery Systems. Adv Mater. 2018, 30 (7), 1704530.

63. Klajn, R., Spiropyran-based dynamic materials. Chem. Soc. Rev. 2014, 43 (1), 148-184.

64. Bléger, D.; Schwarz, J.; Brouwer, A. M.; Hecht, S., oFluoroazobenzenes as Readily Synthesized Photoswitches Offering Nearly Quantitative Two-Way Isomerization with Visible Light. $J$. Am. Chem. Soc. 2012, 134 (51), 20597-20600.

65. Kienzler, M. A.; Reiner, A.; Trautman, E.; Yoo, S.; Trauner, D.; Isacoff, E. Y., A Red-Shifted, Fast-Relaxing Azobenzene Photoswitch for Visible Light Control of an Ionotropic Glutamate Receptor. J. Am. Chem. Soc. 2013, 135 (47), 17683-17686.

66. Higashiguchi, K.; Matsuda, K.; Tanifuji, N.; Irie, M., FullColor Photochromism of a Fused Dithienylethene Trimer. J. Am. Chem. Soc. 2005, 127 (25), 8922-8923.

67. Itel, F.; Chami, M.; Najer, A.; Lörcher, S.; Wu, D.; Dinu, I. A.; Meier, W., Molecular organization and dynamics in polymersome membranes: A lateral diffusion study. Macromolecules 2014, 47 (21), $7588-7596$

68. Discher, D. E.; Eisenberg, A., Polymer vesicles. Science 2002, 297 (5583), 967-973.

69. Eberhardt, M.; Mruk, R.; Zentel, R.; Théato, P., Synthesis of pentafluorophenyl(meth)acrylate polymers: New precursor polymers for the synthesis of multifunctional materials. Eur. Polym. J. 2005, 41 (7), 1569-1575

70. Scherer, M.; Kappel, C.; Mohr, N.; Fischer, K.; Heller, P.; Forst, R.; Depoix, F.; Bros, M.; Zentel, R., Functionalization of Active Ester-Based Polymersomes for Enhanced Cell Uptake and StimuliResponsive Cargo Release. Biomacromolecules 2016, 17 (10), 3305 3317.

71. Perrier, S.; Takolpuckdee, P.; Mars, C. A., Reversible Addition-Fragmentation Chain Transfer Polymerization: End Group 
Modification for Functionalized Polymers and Chain Transfer Agent Recovery. Macromolecules 2005, 38 (6), 2033-2036.

72. Helmy, S.; Leibfarth, F. A.; Oh, S.; Poelma, J. E.; Hawker, C. J.; Read de Alaniz, J., Photoswitching Using Visible Light: A New Class of Organic Photochromic Molecules. J. Am. Chem. Soc. 2014, $136(23), 8169-8172$.

73. Stauch, O.; Schubert, R.; Savin, G.; Burchard, W., Structure of artificial cytoskeleton containing liposomes in aqueous solution studied by static and dynamic light scattering. Biomacromolecules 2002, 3 (3), 565-578.

74. Evans, R. A.; Hanley, T. L.; Skidmore, M. A.; Davis, T. P.; Such, G. K.; Yee, L. H.; Ball, G. E.; Lewis, D. A., The generic enhancement of photochromic dye switching speeds in a rigid polymer matrix. Nat. Mater. 2005, 4 (3), 249.

75. Shima, K.; Mutoh, K.; Kobayashi, Y.; Abe, J., Relationship between activation volume and polymer matrix effects on photochromic performance: bridging molecular parameter to macroscale effect. J. Phys. Chem. A 2015, 119 (7), 1087-1093.
76. Mahajan, S.; Renker, S.; Simon, P. F.; Gutmann, J. S.; Jain, A.; Gruner, S. M.; Fetters, L. J.; Coates, G. W.; Wiesner, U., Synthesis and Characterization of Amphiphilic Poly (ethylene oxide)-block-poly (hexyl methacrylate) Copolymers. Macromol. Chem. Phys. 2003, 204 (8), 1047-1055

77. Weinstein, J.; Yoshikami, S.; Henkart, P.; Blumenthal, R.; Hagins, W., Liposome-cell interaction: transfer and intracellular release of a trapped fluorescent marker. Science 1977, 195 (4277), 489492.

78. Verlander, C., Detection of horseradish peroxidase by colorimetry. Nonisotopic DNA Probe Techniques 1992, 185-201.

79. Bateman Jr, R. C.; Evans, J. A., Using the glucose oxidase/peroxidase system in enzyme kinetics. J. Chem. Educ. 1995, $72(12)$, A240. 


\section{TOC image}

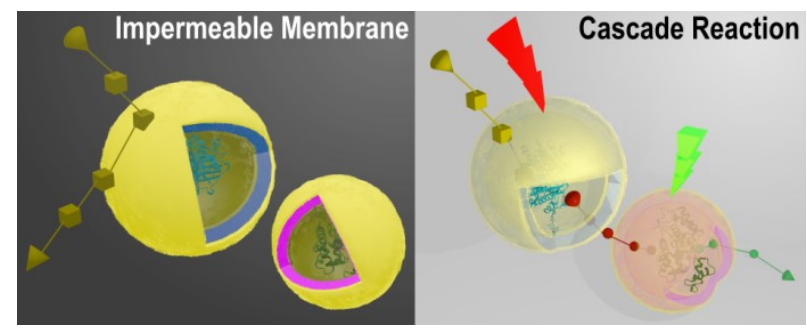

